\title{
Space Suits and Crew Survival Systems Branch Education and Public Outreach Support of NASA's Strategic Goals in Fiscal Year 2012
}

Mallory A. J ennings ${ }^{1}$

NASA J ohnson Space Center, Houston, Texas 77058

As NASA plans to send people beyond low Earth orbit, it is important to educate and inspire the next generation of astronauts, engineers, scientist, and general public. This is so important to NASA future that it is one of the agencies strategic goals. The Space Suits and Crew Survival Systems Branch at J ohnson Space Center (J SC) is actively involved in helping to achieve this goal by sharing our hardware and technical experts with students, educators, and the general public and educating them about the challenges of human space flight, with Education and Public Outreach (EPO). This paper summarizes the Space Suit and Crew Survival Systems Branch EPO efforts throughout fisc al year 2012. 